\title{
Leader-Member Exchange and Organizational Justice in Bahraini Workgroups
}

\author{
Minwir Al-Shammari ${ }^{1, *}$ \& Elham Hasan Ebrahim ${ }^{2}$ \\ ${ }^{1}$ College of Business Administration, University of Bahrain, Kingdom of Bahrain \\ ${ }^{2}$ Lecturer of Management, Kingdom of Bahrain \\ *Corresponding author: College of Business Administration, University of Bahrain, Kingdom of Bahrain. E-mail: \\ minwir@gmail.com
}

Received: November 19, 2014

Accepted: December 4, $2014 \quad$ Online Published: December 10, 2014

doi:10.5430/mos.v2n1p87

URL: http://dx.doi.org/10.5430/mos.v2n1p87

\begin{abstract}
This research aimed at measuring individuals' and workgroups' perceptions of the quality of leader-follower exchange (LMX) and differentiation as well as of organizational justice (OJ) and OC climates. A survey was developed and used. A purposive non-probability sampling method was followed to collect data from 173 employees working in different workgroups that belong to five economic sectors in Bahrain. The individual-level data on LMX and OJ were collected via the survey, were used to examine the relationship between individuals' perceptions of LMX and dimensions of OJ. Later, the individual-level data on LMX and OJ dimensions were aggregated to the group-level of analysis in order to reflect workgroups' perceptions. The study found that individuals' and workgroups' perceptions of OJ were positively related to their perceptions of the level of exchange exerted by a leader toward his/her subordinates.
\end{abstract}

Keywords: leader-member exchange; organizational justice; Bahrain

\section{Introduction}

Humans are valuable assets that contribute to the wellbeing of any people-based system. Their perceptions of fairness and satisfaction with their leaders probably lead to organizational prosperity, while the opposite may create an unhealthy work environment and lead to unwelcomed consequences, e.g., conflict (Lau, 2008).

Leader-Member Exchange (LMX) and Organizational Justice (OJ) are two well known and widely inspected research areas in the field of Organizational Behavior (OB) (Greenberg \& Baron, 2008). A considerable amount of attention has been devoted to the study of both phenomena. This research focuses on examining LMX and OJ dimensions and integrating them in a model that investigates their association at the individual- and group-levels of analysis in an Arabian Gulf cultural context, viz. Bahrain.

Based on LMX, it is assumed that leaders are bounded, by the scarcity of their time and resources, to form relationships of different qualities with their subordinates (Van Breukelen et. al., 2006). Unfortunately, discrimination in the treatment of subordinates was anticipated to provoke feelings of resentment and unfairness between employees (El Akremi, Vandenberghe, \& Camerman, 2010; Lau, 2008). Nevertheless, other researchers suggeted that differntiation, i.e., work-related differentiation, does not neccessarily link to unjustice (Scandura, 1999).

Researchers identified three justice dimensions that individuals care about in any organizational setting, i.e., Procedural Justice (PJ), Interactional Justice (IJ), and Distributive Justice (DJ). These three dimensions were used by employees to judge the fairness of organizational procedure implementation, interpersonal treatment, and reward distribution, e.g., payment, respectively (Colquitt, et. al., 2005). 


\section{Objectives of the Study}

The objectives of the study were as follows:

- To measure individuals' perceptions of the quality of leader-follower relationships.

- To measure individuals' perceptions of OJ with regards to reward distribution, procedure implementation, and interpersonal treatment, i.e., DJ, PJ, and IJ respectively.

- To discover workgroups' perceptions of LMX Level and LMX Differentiation.

- $\quad$ To measure workgroups' perceptions of OJ Climates, i.e., DJ Climate, PJ Climate, and IJ Climate.

\section{Importance of the Study}

This research makes different contributions to the existing literature on LMX and OJ. First, it examines LMX and OJ in a new cultural setting that has rarely been examined by researchers interested in both fields, i.e., Kingdom of Bahrain. Through this research, perceptions of OJ dimensions and LMX are examined in a context other than Western cultures, i.e., Kingdom of Bahrain. This kind of examination is quite important given the common existing belief that leadership practices cannot be readily transferred between different cultures (Shahin \& Wright, 2004).

Examining justice perceptions in group-oriented cultures, e.g., Asian, rather than individualistic ones is important (Hayashi \& Sekiguchi, 2006), especially since the number of studies which have integrated LMX and OJ among groups in non-Western cultures is limited (Bolat, 2010).

\section{Previous Studies}

\subsection{Leader-Member Exchange}

Graen and Uhl-Bien (1995) posited that LMX theory has gone through four evolutionary stages, which are as follows:

- Stage 1 (Vertical dyad linkage): this stage focused on the dyadic relationship between leaders and their subordinates. Contrary to what was suggested by the average leadership style theory, it was found that leaders sometimes differentiate in their working relationship with their subordinates (Dansereau et. al., 1975). While some subordinates may have high levels of mutual trust and respect, other members may report the lack of such trust and respect with the same leaders (Graen et. al., 1982). This stage witnessed a departure from the initial focus on the leaders' behavior to focusing on the leader-follower dyads relationship, with the dyads as the unit of analysis.

- Stage 2 (LMX): scholars at this stage were involved in two primary activities, investigating LMX characteristics and relating LMX to organizational outcomes. It was at this stage also that LMX, rather than vertical dyad linkage, was used as a term to express the exchange relationship between leaders and followers.

- Stage 3 (Leadership-making): essentially this stage focused on the formation of "high-quality" LMX relationships between leaders and subordinates, rather than on discriminating LMX relationships into "high-quality" and "low-quality", thereby increasing leadership effectiveness. The leadership making model was developed at this stage to prescribe how "high-quality" relationships can be produced in real life.

- Stage 4 (Team-making competence network): previously, LMX was examined in term of isolated dyads with little attention to the collective nature of communication between leaders and multiple subordinates in the workplace. However, it was at this stage that analysis shifted from dyads to workgroups and organizations, i.e., aggregation of dyads, in order to examine the predictability of important group and organizational outcomes (Mayer, 2004).

DeChurch et. al. (2010) investigated empirical research on leadership by looking at 2,031 articles published in 11 journals, covering a time span of 25 years. Their study included articles that linked leadership to outcomes residing at the individual, team, unit, and organizational levels of analysis. It was found that LMX research was mainly concerned with managers at lower hierarchal levels (32\%), where leadership is mostly composed of tasks such as hiring, firing, and task allocation. This was followed by studies at the middle and top levels of management.

Moreover, a considerable amount of empirical research has been conducted to identify antecedents of LMX (Dulebohn et. al., 2011; Van Breukelen et. al., 2006). According to those studies, it was found that leaders' behaviors 
and characteristics had a greater influence on the quality of LMX than those of the followers (Dulebohn et. al., 2011). In addition, the previous researchers suggested that the quality of LMX could be further enhanced with the application of contingent rewards and transformational leadership; since such behaviors usually indicate the leaders' commitment to their followers, as well as their genuine wish to focus on relationship development, which encourages followers to respond back with additional effort in order for the relationship to flourish.

Dulebohn et. al. (2011) found that LMX was positively related to followers' competence and positive affectivity, i.e., enthusiasm and optimism, agreeableness, extraversion, i.e., sociability and ambition, conscientiousness, i.e., achievement and dependability, and locus of control, i.e., control over outcomes, and negatively to followers' negative affectivity, i.e., hostility and negativism.

\subsection{Organizational Justice}

For centuries, justice has won the interest of people all over the world (Colquitt et. al., 2005). The belief that an association between perceived fair treatment and organizational attitudes and individual outcomes had a tremendous impact on the field of OJ, so much so that it became the subject of various research and investigations (Colquitt et. al., 2001; Roch \& Shanock, 2006). Unfortunately, it is often contended that OJ tends to be subjective, due to the fact that it focuses on an individual's perception of fairness in the workplace (Greenberg, 1987; Li \& Cropanzano, 2009).

$\mathrm{OJ}$ is a multi-dimensional construct that consists of the following dimensions:

- DJ: According to Andrews and Kacmar (2001), DJ can be defined as "the perceived fairness of the allocation of resources by the organization" (p. 349).

- PJ: This dimension focuses on the fairness of the procedures, methods, mechanisms, and rules that leaders follow during decision making (Thibaut \& Walker, 1975).

- IJ: This dimension of OJ is concerned with the fairness of the interpersonal treatment received by an individual from others (Bies \& Moag, 1986).

\section{Method}

This study was based on the models proposed by Lau (2008) and Mayer (2004). Lau (2008) developed two models to study the relationships between LMX and OJ dimensions at the individual- and group-levels of analysis, while Mayer (2004) examined the relationships between LMX and OJ Climates at the group-level of analysis.

A purposive non-probability sampling was used to construct the study sample. Given that the survey was in English, only respondents who were capable of reading and comprehending English text were selected. In addition, participants had to be working in groups consisting of at least two members.

Out of 372 employees compromising the targeted groups, 173 employees responded to the questionnaires with useable answers, i.e., an average participation rate (47\%). The individual-level data on LMX and OJ dimensions were aggregated to the group-level of analysis in order to reflect workgroups' perceptions.

\section{Results}

\subsection{Scale Reliability}

The surveys used in this research were tested for their reliability by calculating the Cronbach alpha coefficient $(\alpha)$ for each and for the overall questionnaire. Results of reliability test are listed in Table 1 . The overall reliability of the model was estimated with $\alpha=.94$. In addition, each of the measures used reported a high reliability (LMX, $\alpha=.86$; DJ, $\alpha=.71 ;$ PJ and IJ, $\alpha=.81$ for each).

Table 1. Results of Cronbach Alpha Scale Reliability Test

\begin{tabular}{lcc}
\hline Scale & Cronbach alpha & No. of items \\
\hline LMX & .86 & 7 \\
DJ & .71 & 3 \\
PJ & .81 & 5 \\
IJ & .81 & 5 \\
Overall & .94 & 20 \\
\hline
\end{tabular}




\subsection{Individual and Workgroup Characteristics}

Table 2 shows the demographic characteristics of the respondents. More than half of the participants (58\%) were males. Additionally, the majority were college or university graduates, with bachelor degree holders compromising (64\%). In terms of religion, most of the respondents were Muslims (84\%), while the remaining were Christians (7\%), Hindus $(8 \%)$, and only two respondents $(1 \%)$ chose "others" as an answer to this question. Nearly half of the respondents were working in the industrial sector (47\%) followed by those in the education sector (24\%). Moreover, the respondents were distributed across different professions. Teaching and engineering are some of the professions in which the participated employees were working.

Table 2. Demographic Distribution of Participants

\begin{tabular}{llll}
\hline Category & Description & No. & $\%$ \\
\hline Gender & Males & 101 & $58.40 \%$ \\
& Females & 72 & $41.60 \%$ \\
\hline \multirow{2}{*}{ Education } & Totals & 173 & $100 \%$ \\
& Diploma or below & 40 & $23.10 \%$ \\
& Bachelor & 110 & $63.60 \%$ \\
& Master and above & 23 & $13.30 \%$ \\
\hline Religion & Totals & 173 & $100 \%$ \\
& Muslims & 146 & $84.40 \%$ \\
& Christians & 12 & $6.90 \%$ \\
& Hindus & 13 & $7.50 \%$ \\
\hline Profession & Others & 2 & $1.20 \%$ \\
& Totals & 173 & $100 \%$ \\
& Accounting and Finance & 19 & $10.98 \%$ \\
& HR and Administration & 23 & $13.29 \%$ \\
& Teaching & 42 & $24.28 \%$ \\
& IT Professionals & 12 & $6.94 \%$ \\
& Sales and Marketing & 24 & $13.87 \%$ \\
& Engineering & 27 & $15.61 \%$ \\
& Processing and Operation & 26 & $15.03 \%$ \\
\hline & Totals & 173 & $100 \%$ \\
\hline
\end{tabular}

Table 3 shows some characteristics of the investigated workgroups. The sample consisted of 42 workgroups distributed across five economic sectors. It was dominated by groups of ten or less members ( $80.95 \%)$. Additionally, more than one fifth of these workgroups were involved in the teaching profession $(21.43 \%)$, followed by processing and operation teams $(16.67 \%)$.

Table 3. Distribution of Workgroups According to Group Size and Demographics

\begin{tabular}{llll}
\hline Category & Description & No. & $\%$ \\
\hline Workgroup size & $2-5$ & 20 & $47.62 \%$ \\
& $6-10$ & 14 & $33.33 \%$ \\
& $11-15$ & 5 & $11.91 \%$ \\
& $>15$ & 3 & $7.14 \%$ \\
\hline Participants' Profession & Totals & 42 & $100 \%$ \\
& Accounting and Finance & 6 & $14.29 \%$ \\
& HR and Administration & 6 & $14.29 \%$ \\
& Teaching & 9 & $21.43 \%$ \\
& IT Professionals & 4 & $9.52 \%$ \\
& Sales and Marketing & 4 & $9.52 \%$ \\
& Engineering & 6 & $14.29 \%$ \\
& Processing and Operation & 7 & $16.66 \%$ \\
\hline Participants' Gender & Totals & 42 & $100 \%$ \\
& Majority are Males & 25 & $59.53 \%$ \\
& Majority are Females & 13 & $30.95 \%$ \\
& Others & 4 & $9.52 \%$ \\
\hline
\end{tabular}




\begin{tabular}{llll}
\hline & Totals & 42 & $100 \%$ \\
\hline Participants' Education & Majority hold a Diploma or below degrees & 7 & $16.67 \%$ \\
& Majority hold a Bachelor degree & 26 & $61.90 \%$ \\
& Majority hold a Master and above degrees & 3 & $7.14 \%$ \\
& Others & 6 & $14.29 \%$ \\
\hline & Totals & 42 & $100 \%$ \\
\hline Participants' Religion & Majority are Muslims & 36 & $85.72 \%$ \\
& Majority are Christians & 1 & $2.38 \%$ \\
& Majority are Hindus & 2 & $4.76 \%$ \\
& Others & 3 & $7.14 \%$ \\
\hline & Totals & 42 & $100 \%$
\end{tabular}

The lowest contribution in the sample was made by IT groups and sales and marketing groups, each consisted $(9.52 \%)$ of the sample workgroups. Most of the teams were composed of males (59.53\%). Moreover, more than half of the workgroups had the majority of their participants holding Bachelor degrees (61.90\%). Finally, Islam was dominating the religious background of the workgroups, 36 workgroups had the majority of their participants being Muslims.

\subsection{Perceptions of Leader-Member Exchange and Organizational Justice}

Table 4 illustrates that the participants reported average to high levels of $\operatorname{LMX}($ Mean $=3.71$, Mode $=4.14, \mathrm{SD}=.86)$ and justice perceptions (DJ, Mean = 3.51, $\mathrm{SD}=1.00$; PJ, Mean = 3.61, $\mathrm{SD}=.89$; IJ, Mean = 3.66, $\mathrm{SD}=1.02$ ). The investigated workgroups had average to high levels of LMX (Mean $=3.66$, Mode $=4.00, \mathrm{SD}=.61)$. Furthermore, leaders did not differentiate aggressively between members within those groups. Low levels of LMX Differentiation were identified in the current study (Mean $=.68, \mathrm{SD}=.29$ ). OJ Climates were also above the average (DJ Climate, $\mathrm{M}=3.46, \mathrm{SD}=.76$; PJ Climate, Mean $=3.56, \mathrm{SD}=.64$; IJ Climate, $\mathrm{Mean}=3.59, \mathrm{SD}=.71$ ).

Table 4 shows that the participating workgroups had an average size of 8 members and were considerably variant in this term $($ Mean $=7.74$, Median $=6, \mathrm{SD}=6.31)$. The maximum group size was 29 members and the minimum was 2 . Moreover, they were overall moderately homogeneous (workgroup heterogeneity overall, Mean $=.24$, Mode $=.00$, SD $=.27$ ). The greatest diversity stemmed from educational background (Mean $=.24, \mathrm{SD}=.24$ ), while more homogeneity was observed in terms of gender and religion (workgroup heterogeneity gender, Mean =.14, $\mathrm{SD}=.21$; workgroup heterogeneity religion, Mean $=.15, \mathrm{SD}=.22$ ).

Table 4. Descriptive Statistics of the Study Variables

\begin{tabular}{llllllll}
\hline Variable & Mean & Median & Mode & Max & Min & Range & SD \\
\hline LMX & 3.71 & 3.86 & 4.14 & 5.00 & 1.29 & 3.71 & .86 \\
DJ & 3.51 & 3.67 & 4.00 & 5.00 & 1.33 & 3.67 & 1.00 \\
PJ & 3.61 & 3.60 & 3.60 & 5.00 & 1.00 & 4.00 & .89 \\
IJ & 3.66 & 3.80 & 5.00 & 5.00 & 1.40 & 3.60 & 1.02 \\
LMX Level & 3.66 & 3.76 & 4.00 & 4.63 & 1.79 & 2.85 & .61 \\
LMX Differentiation & .68 & .65 & .49 & 1.21 & .10 & 1.11 & .29 \\
DJ Climate & 3.46 & 3.65 & 4.00 & 4.67 & 1.42 & 3.25 & .76 \\
PJ Climate & 3.56 & 3.69 & 3.33 & 4.51 & 1.70 & 2.81 & .64 \\
IJ Climate & 3.59 & 3.77 & 3.87 & 4.86 & 1.70 & 3.16 & .71 \\
workgroup heterogeneity education & .24 & .30 & .00 & .64 & .00 & .64 & .24 \\
workgroup heterogeneity gender & .14 & .00 & .00 & .50 & .00 & .50 & .21 \\
workgroup heterogeneity religion & .15 & .00 & .00 & .67 & .00 & .67 & .22 \\
workgroup heterogeneity overall & .28 & .22 & .00 & .78 & .00 & .78 & .27 \\
workgroup size & 7.74 & 6.00 & 4.00 & 29.00 & 2.00 & 27.00 & 6.31 \\
\hline
\end{tabular}

Workgroups' perceptions of the quality of employees' exchanges with their leaders and the level of OJ they received were identified both individually and workgroup-wide. The means of LMX, OJ dimensions, and OJ Climates were all higher than the scales midpoint. At the same time, low levels of discrimination, i.e., LMX Differentiation, were reported by the study sample. These obtained levels of LMX, OJ, and OJ Climates indicate that leaders in Bahraini workgroups can be distinguished for caring for their relationships with their workgroup members and of being fair with them.

Furthermore, the fact that the examined sample reported above average levels of PJ and PJ Climate suggests that managers in the investigated organizations were actually accredited the control over the design and implementation 
of the applied organizational procedures (Masterson et. al., 2000). Alternatively, it could be attributed to a potential overlap, among individuals and workgroups, concerning PJ and IJ (Erdogan et. al., 2006), especially since a significant positive relation was reported between these justice dimensions at both levels of analysis.

Additionally, when it comes to DJ and DJ Climate, those high scores could be attributed to two primary reasons. First, in the current study, both government and non-government organizations were investigated, while in other studies, e.g., Andrews and Kacmar (2001), only government organizations, where the power of reward distribution was not handed to first line managers, were approached. Second, not all of the items in the original DJ measure were used in the present research; rather only three of the original items developed by Niehoff and Moorman (1993) were included to ensure that employees would evaluate their leaders based on the outcomes they actually controlled, ultimately affecting respondents' perceptions of this justice dimension.

Looking at the group-level findings alone, the aggregation statistics results, e.g., median $r_{w g(j)}$, concerning LMX, PJ, DJ, and IJ supports the impact of group membership on developing shared group cognition based on individual observations. Furthermore, the values generated from the ICC(1) statistical procedure indicated that more than a quarter $(27 \%)$ of individuals' perceptions of LMX, PJ, and IJ could be attributed to group membership, while more than third (36\%) of DJ perceptions are affected by workmates. This is consistent with the findings of Colquitt et. al. (2004) regarding PJ, that individual justice perceptions are affected by group membership. Furthermore, the current results extend Colquitt's findings beyond PJ to include LMX and the remaining OJ Climates.

The group level results support social theories that suggest the important role played by group membership in shaping individuals' perceptions regarding their work environment. Such theories include: justice contagion, heuristic model, social information processing, and socialization theories (Li \& Cropanzano, 2009; Salancik \& Pfeffer, 1978; and Schneider \& Reichers, 1983).

The higher the number of high quality exchanges in a given workgroup, the more that members would share positive views of their leaders' treatment with each other, spreading a sense of having the whole group being treated with high quality (Mayer, 2004). Furthermore, when members of a workgroup perceive their leaders to be equally just while implementing procedures, treating them, and distributing information and resources, they are likely to share these perceptions with each other and a common belief of the leaders' fairness is likely to overwhelm the group (Colquitt et. al., 2002; Colquitt, et. al. 2004; Lau, 2008; Mayer, 2004). Given that the participating workgroups were relatively small in size and demographically homogeneous, it is no wonder that the impact of socialization processes was augmented, and that members of the workgroup tended to share similar points of view regarding the study variable as supported by the Selection Attraction Attrition theory (Schneider \& Reichers, 1983).

Finally, the reported low levels of LMX Differentiation suggested that leaders did not differentiate aggressively between their workgroup members. They actually tended to focus on the development of high quality exchanges while at the same time exhibiting a certain level of consistency in treatment to the limit that differentiation would not be encountered as being persuasive, but perceived as minor, or as a legitimate act based on individual differences in capabilities.

\section{Conclusions and Recommendations}

\subsection{Conclusions}

Several conclusions can be derived from the work done. First, leadership practices have a valuable impact on individuals and workgroups perceptions of workplace. Hence, leaders and followers need to focus on nurturing the quality of their relationships to further promote employees' perceptions of fair distribution of resources, interpersonal treatment, and enactment of procedures both at the individual- and group-level.

Second, workgroups are an important part of the work environment, focusing on group related issues and dynamics is necessary to promote organizational life. Differentiation in treatment between workgroup members does not necessarily provoke feelings of injustice, especially if care was taken while doing so, and only limited levels of differentiation were exhibited.

Third, large group size and diversity do not necessitate that leaders are incapable of developing high quality relations with their group members or to treat them in a fair manner. Contrarily, the role of LMX on Justice Climates' perceptions was not proven to be moderated by these two group characteristics.

Finally, leadership practices cannot be exactly replicated from one cultural setting to the other, although a consistency of results has been found by Arab world cultures, i.e. Bahrain, with regards to LMX quality and OJ both 
individually and group wide. However, this similarity still did not extend to LMX Differentiation, suggesting that other aspects, e.g., culture, may play an important role in shaping groups perceptions of justice.

\subsection{Recommendations for Future Research}

It is recommended that the impact of workgroup size and heterogeneity needs to be re-examined, focusing on groups of larger sizes and greater heterogeneity. Furthermore, other moderators should be verified for their potential role on LMX and justice perceptions, especially culture. Individual-level moderators' cross-level interaction of both individual- and group-level variables should also be examined.

\section{References}

Andrews, M. C., \& Kacmar, K. M. (2001). Discriminating among organizational politics, justice, and support. Journal of Organizational Behavior, 22(4), 347-366. http://dx.doi.org/10.1002/job.92

Bies, R. J., \& Moag, J. F. (1986). Interactional justice: Communication criteria of fairness. In R. J. Lewicki, B. H. Sheppard, \& M. H. Bazerman (Eds.), Research on negotiations in organizations (Vol. 1, pp. 43-55. Greenwich, CT, United States: JAI Press.

Bolat, O. I. (2010). The relationships between leader-member exchange and Organizational Justice in hotels. European Journal of Economics, Finance and Administrative Sciences, 26, 115-125.

Colquitt, J. A., Conlon, D. E., Wesson, M. J., Porter, C. O., \& Ng, K. Y. (2001). Justice at the millennium: A meta-analytic review of 25 years of organizational justice research. Journal of Applied Psychology, 86(3), 425-445. http://dx.doi.org/10.1037/0021-9010.86.3.425

Colquitt, J. A. (2001). On the dimensionality of organizational justice: A construct validation of a measure. Journal of Applied Psychology, 86(3), 386-40. http://dx.doi.org/10.1037/0021-9010.86.3.386

Colquitt, J. A., Noe, R. A., \& Jackson, C. L. (2002). Justice in teams: Antecedents and consequences of procedural justice climate. Personnel Psychology, 55, 83-109. http://dx.doi.org/10.1111/j.1744-6570.2002.tb00104.x

Colquitt, J. A. (2004). Does the justice of the one interact with the justice of the many? Reactions to procedural justice in teams. Journal of Applied Psychology, 89(4), 633-646. http://dx.doi.org/10.1037/0021-9010.89.4.633

Colquitt, J. A., Greenberg, J., \& Zapata-Phelan, C. P. (2005). What is organizational justice? A historical overeview. In J. Greenberg, \& J. A. Colquitt (Eds.), Handbook of Organizational Justice (pp. 3-58). New Jersy, United States: Lawrence Erlbaum.

Creswell, J. W. (2003). Research design: Qualitative, quantitative, and mixed methods approaches (2nd ed.). Thousand Oaks, California, United States: Sage Publications, Inc.

Creswell, J. W. (1994). Research design: Quantitative \& qualtitative approaches. Thousand Oaks, California, United States: Sage Publications.

Dansereau, F. J., Graen, G. B., \& Haga, W. J. (1975). A vertical dyad linkage approach to leadership within formal organizations: A longitudinal investigation of the role making process. Organizational Behavior and Human Performance, 13(1), 46-78. http://dx.doi.org/10.1016/0030-5073(75)90005-7

DeChurch, L. A., Hiller, N. J., Murase, T., Doty, D., \& Salas, E. (2010). Leadership across levels: Levels of leaders and their levels of impact. The Leadership Quarterly, 21(6), 1069-1085. http://dx.doi.org/10.1016/j.leaqua.2010.10.009

Dulebohn, J. H., Bommer, W. H., Liden, R. C., Brouer, R. L., \& Ferris, G. R. (2011). A meta-analysis of antecedents and consequences of leader-member exchange: Integrating the past with an eye toward the future. Journal of Management, 20(5), 1-45.

El Akremi, A., Vandenberghe, C., \& Camerman, J. (2010). The role of justice and social exchange relationships in workplace deviance: Test of a mediated model. Human Relations, 63(11), 1687-1717. http://dx.doi.org/10.1177/0018726710364163

Erdogan, B., Liden, R. C., \& Kraimer, M. L. (2006). Justice and Leader MemberExchange: The Moderating Role of Culture. Academy of Management Journal, 49(2), 395-406. http://dx.doi.org/10.5465/AMJ.2006.20786086

Graen, G. B., Liden, R. C., \& Hoel, W. (1982). Short notes role of leadrship in the employee withdrawal process. Journal of Applied Psychology, 67(6), 868-872. http://dx.doi.org/10.1037/0021-9010.67.6.868 
Graen, G. B., \& Uhl-Bien, M. (1995). Relationship-based approach to leadership: Development of leader-member exchange $(\operatorname{lmx})$ theory of leadership over 25 years: Applying a multi-level multi-domain perspective. Leadership Quarterly, 6(2), 219-247. http://dx.doi.org/10.1016/1048-9843(95)90036-5

Greenberg, J. (1987). A taxonomy of organizational justice theories. The Academy of Management Review, 12(1), 9-22.

Greenberg, J., \& Baron, R. A. (2008). Behavior in organizations (9th ed.). New Jersey, United States: Pearson Education Inc.

Guzzo, R. A., \& Dickson, M. W. (1996). Teams in organizations: Recent research on performance and effectiveness. Annual Review of Psychology, 47, 307-338. http://dx.doi.org/10.1146/annurev.psych.47.1.307

Hayashi, Y., \& Sekiguchi, T. (2006). Collective justice perceptions in group-oriented cultures: Proposal of a new construct. The Japanese Journal of Administrative Science, 19(3), 207-219. http://dx.doi.org/10.5651/jaas.19.207

Lau, R. S. (2008). Integration and extension of leader-member exchange and organizational justice at individualand group-levels of analysis. Doctoral Dissertation, Virginia Polytechnic Institute and State University, Blacksburg, VA.

Li, A., \& Cropanzano, R. (2009). Fairness at the group-level: Justice climate and intraunit justice climate. Journal of Management, 35(3), 564-599. http://dx.doi.org/10.1177/0149206308330557

Masterson, S. S., Lewis, K., Goldman, B. M., \& Taylor, M. S. (2000). Integrating justice and social exchange: The differing effects of fair procedures and treatment on work relationships. The Academy of Management Journal, 43(4), 738-748. http://dx.doi.org/10.2307/1556364

Mayer, D. M. (2004). Are you in or out? A group-level examination of the effects of LMX on justice and customer satisfaction. Doctoral Dissertation, University of Maryland, Graduate School of the University of Maryland, College Park, Maryland.

Niehoff, B. P., \& Moorman, R. H. (1993). Justice as a mediator of the relationship between methods of monitoring and organizational citizenship behavior. The Academy of Management Journal, 36, 527-556. http://dx.doi.org/10.2307/256591

Roch, S. G., \& Shanock, L. R. (2006). Organizational justice in an exchange framework: Clarifying organizational justice distinctions. Journal of Management, 32(2), 299-322. http://dx.doi.org/10.1177/0149206305280115

Salancik, G. R., \& Pfeffer, J. (1978). A social information processing approach to job attitudes and task design. Administrative Science Quarterly, 23(2), 224-253. http://dx.doi.org/10.2307/2392563

Scandura, T. A. (1999). Rethinking leader-member exchange: An Organizational justice perspective. Leadership Quarterly, 10(1), 25-4. http://dx.doi.org/10.1016/S1048-9843(99)80007-1

Schneider, B., \& Reichers, A. E. (1983). On The etiology of climates. Personnel Psychology, 36, 19-39. http://dx.doi.org/10.1111/j.1744-6570.1983.tb00500.x

Shahin, A., \& Wright, P. (2004). Leadership in the context of culture: An Egyptian perspective. Leadership \& Organization Development Journal, 25(6), 499-511. http://dx.doi.org/10.1108/01437730410556743

Sparrowe, R. T., \& Liden, R. C. (1997). Process and structure in leader-member exchange. The Academy of Management Review, 22(2), 522-552.

Thibaut, J. W., \& Walker, L. (1975). Procedural justice: A psychological perspective. Hillsdale, NJ, USA: Lawrence Erlbaum.

Van Breukelen, W., Schyns, B., \& Le Blanc, P. (2006). Leader-member exchange theory and research: Accomplishments and future challenges. Leadership, 2(3), 295-316. http://dx.doi.org/10.1177/1742715006066023 